\title{
437.
}

\section{DÉMONSTRATION NOUVELLE DU THÉORÈME DE M. CASEY PAR RAPPORT AUX CERCLES QUI TOUCHENT À TROIS CERCLES DONNÉS.}

[From the Annali di Matematica pura ed applicata, tom. I. (1867), pp. 132-134.]

ThIs is in fact the investigation contained in the paper 414, "On Polyzomal Curves otherwise the curves $\sqrt{ } U+\sqrt{V}+\& c .=0$," Annex II. pp. 568-573, "On Casey's theorem for the circle which touches three given circles," viz. it is based on the identity of the two problems $1^{\circ}$ to find a circle touching three given circles, $2^{\circ}$ to find a cone-sphere (sphere of radius zero) passing through three given points in space. 